\title{
The effect of self-employment on health, access to care, and health behavior
}

\author{
Jangho Yoon ${ }^{*}$, Stephanie L. Bernell \\ Health Management and Policy Program, College of Public Health and Human Sciences, Oregon State University, Corvallis, USA; \\ *Corresponding Author: jangho.yoon@oregonstate.edu
}

Received 6 November 2013; revised 6 December 2013; accepted 16 December 2013

Copyright (C) 2013 Jangho Yoon, Stephanie L. Bernell. This is an open access article distributed under the Creative Commons Attribution License, which permits unrestricted use, distribution, and reproduction in any medium, provided the original work is properly cited.

\begin{abstract}
The focus of this paper is to investigate the role self-employment conceptualized as a lifestyle factor on health, access to health care, and health behaviors. We analyze rich data on 13,435 working adults in the US, who are either selfemployed or salaried workers. Outcomes include physical and mental health perception, validated indexes of physical and mental health, and medical conditions; access-to-care measures such as a barrier to obtaining necessary health care; and health behaviors such as smoking, physical activity and body mass index. Instrumental variables methods are used to correct for selection into self-employment. We find that self-employment is positively associated with perceived physical health, and is negatively associated with having diabetes, high blood pressure, high cholesterol and arthritis. No mental health outcome is significantly associated with self-employment. There is no significant difference between self-employed and wage-earning individuals with regard to access to care. Selfemployed individuals are less likely to smoke, and are more likely to participate in physical activity and have normal-weight. We conclude that despite lack of health insurance, self-employed persons in the US are as healthy as wage-earners, do not experience a greater barrier to access to care, and are more likely to engage in healthy behavior.
\end{abstract}

Keywords: Self-Employment; Health; Health Behavior; Access to Care; Health Determinant

\section{INTRODUCTION}

Based on the amount of money that is spent on health services in the US, one might assume that access to health care services and the quality of health services are the primary drivers of health. Although these factors do play a role, federal and local policies, social and physical conditions of the environment, and biology and genetics must also be considered. Moreover, individual behavior or what is sometimes referred to as "lifestyle" has been shown by many researchers to be one of the most important determinants of health [1].

The term "lifestyle" is a catch-all term that typically refers to behaviors such as smoking, diet, drug use, exercise, and even sleep. In this paper, we empirically examine the role of self-employment, conceptualized as a lifestyle factor, on health. The daily rhythm and financial expectations of self-employed individuals is very different from that of wage earners. While wage-earning individuals have the benefit of consistent earnings, being self-employed can give individuals greater work autonomy, flexibility, and the expectation of higher financial rewards [2]. These general features may explain higher job and life satisfaction among the self-employed compared to wage-earners [2-6].

Theoretically, self-employed individuals may experience better health due to the positive association between health and life satisfaction (Binder and Coad, 2010). On the other hand, self-employed individuals face more demands regarding operating their own business (e.g., longer work hours, more decision-making responsibility and stress attributable to market uncertainty). The potential financial, physical and mental stressors among the self-employed can lead to more physical and mental health problems [7].

This study has two primary goals. The first is to investigate health difference (both physical and mental) between the self-employed and wage-earning populations. We analyze a nationally representative sample of US working adults. Instrumental variables approaches are utilized to deal with the fact that employment choice may 
affect health, and vice versa (i.e., endogeneity of selfemployment). Prior research does not account for this important selection issue [5]. To increase the richness of the study, we use both perceived measures and validated indexes of physical and mental health as well as a set of clinical conditions of physical health.

The second goal of the study is to explore potential explanations for health difference (or no difference in health) between the two populations. We test whether, after accounting for the self-selection issue, self-employment is associated with unequal access to health care or different health-related behavior.

The contemporary US represents an interesting site for a test of the potential pathways through which self-employment may influence health. In the US, self-employment has been linked to a significantly greater risk of being uninsured as compared to wage-earning [8-10]: the self-employed are currently twice as likely as wageearning individuals to be uninsured [9]. In this circumstance, self-employment might relate to worse health outcomes if the lack of health insurance among the selfemployed hampers them from obtaining access to health care at the time of need. Meanwhile, certain job characteristics unique to self-employment such as greater autonomy and flexibility might be attached to health behaviors different from those of wage-earners.

The Affordable Care Act of 2010 and the Supreme Court's decision in June 2012 in the US will alter the health insurance landscape significantly beginning in January 2014 [11]. Having a clear sense of the health disparities and role of health insurance and health behavior on health production is essential to understand how far the Affordable Care Act can go in terms of reducing health disparities between wage earners and the self-employed.

\section{RELATIONSHIP BETWEEN SELF-EMPLOYMENT AND HEALTH}

The literature remains inconclusive about a link between self-employment and health, showing substantial within and cross-country variations. Swedish self-employed individuals have more mental health conditions than wage-earners [5]. Israeli self-employed workers experience greater work-related stress than wage-earners [12]. In Germany, the self-employed reportedly have fewer mental health problems [13]. Similarly, analyses of data on workers in the US and European countries find a significant association between self-employment and greater job and life satisfaction $[2,4,6,14]$. In Canada, no difference in mental health is found between self-employed and wage-earning individuals [15].

There is no clear-cut pattern as well in terms of physical health differences. In Sweden, there is no difference in reported general health status between the self-em- ployed and wage-earners [5]. German self-employed workers are physically healthier, e.g., lower blood pressure and less hypertension cases [13]. Self-employed males in Israel appear to be physically unhealthier than their wageearning counterparts [12].

Little research has examined a relationship between self-employment and health in the US. Dolinsky and Caputo [16] find that among female workers, self-employed persons report worse subjective health than their wage-earning counterparts. Perry and Rosen [17] is particularly noteworthy. They analyze a nationally representative sample of US working adults in 1996 to investigate difference between self-employed and wage-earners in term of health insurance coverage and health status. They report that despite the significant lack of health insurance among the self-employed, no difference in health status is found between the two groups as measured by general health perception and several medical conditions such as cancer, heart disease, and respiratory condition.

Despite the contributions to the literature, several limitations in the literature make it difficult to conclude that self-employment does or does not relate to health disparity in the contemporaneous US.

First, findings from the international data on health differential between self-employed and wage-earning individuals cannot be easily applicable to the US due to cross country differences.

Second, most existing studies are cross-sectional in nature, and therefore their findings are likely to be limited in terms of causal inference. In particular, the potential omitted variable bias and reverse causality from health status to employment choice are not directly addressed. For instance, Perry and Rosen [17] finding might be due to "self-selection" into self-employment by healthy persons, which could occur when healthier persons are more likely to choose self-employment rather than to work for others.

Third, results from the US-based studies may not be applicable to today's state of affairs. During the last decades, minorities and women's participation in the selfemployment workforce have increased significantly [18]. Given that health disparities by race/ethnicity and gender continue to exist, the demographic changes in the selfemployed population might signal a new era of health disparities between the self-employed and wage-earning populations.

Fourth, self-employed persons in the US may obtain equal access to necessary health care services through self-insurance despite their lack of health insurance [19]. In this scenario, an employment status (i.e., self-employment vs. wage-earning) may not lead to any health difference as long as the lack of health insurance does not worsen access to health care among the self-employed. 
Alternatively, self-employed individuals may be more likely than wage-earning counterparts to engage in health behavior perhaps due to more flexibility and autonomy of self-employment.

This study addresses the limitations in the literature, employing a method that directly corrects for the simultaneity of self-employment and health, and also testing for unmet health care need and health behavior as mechanisms that link self-employment and health.

\section{DATA}

\subsection{Sample}

The sample for this study is derived from the household component of the 2007 Medical Expenditure Panel Survey (MEPS). The MEPS is a nationally representative survey of the US civilian non-institutionalized population, and provides rich information on health status, medical conditions, employment, health insurance coverage, and socio-demographic characteristics of respondents. The MEPS uses a complex survey design that features stratified and multi-stage sampling and the oversampling of certain groups such as minorities and lowincome families. Respondents were preliminarily interviewed in the beginning of 2007 (Round 1). Two followup interviews (Rounds 2 and 3 interviews) were conducted during calendar year 2007. All information is derived from the Round 2 interview unless mentioned otherwise.

The original sample contains 30,964 individuals. The elderly aged 65 and over and children under 18 are excluded from the analysis which deletes 13,369 observations. We drop from the sample 4037 unemployed individuals and 123 individuals who provided no information on employment status. The final analytic sample includes 13,435 individuals, either self-employed or wage-earning individuals.

\subsection{Measures of Physical and Mental Health}

Variables used in this study are reported in Table 1. We discuss their descriptive statistics in the result section.

Measures for physical and mental health include both health perception and validated scores, as well as a set of medical conditions. Health perception measures include perceived physical health status and perceived mental health status. Both variables take the ordinal values from 1 (poor health) to 5 (excellent health). Validated physical health indexes include the Physical Health Composite Scores derived from the Short-Form 12 Version 2 (SF$12 \mathrm{v} 2$ ). We also examine a set of prevalent life-threatening or chronic medical conditions such as stroke, diabetes, asthma, high blood pressure, high cholesterol, emphysema, joint pain, and arthritis. Validated mental health measures include the Mental Health Composite Scores calculated from the SF-12v2, and the Kessler Index of non-specific psychological distress. Physical Health Composite Scores, Mental Health Composite Scores, and Kessler Index are derived from the Round 2 interview while other health outcomes are obtained from the Round 3 interview.

The SF-12v2 is a short form survey with 12 questions selected from the SF-36 Health Survey [20]. It is a valid shorter alternative to the SF-36. Responses to 12 health questions are combined and weighted to create two scales that provide easily interpretable scores for physical and mental health. Physical Health Composite Score is calculated by weighting the physical items of the SF-12v2 more heavily while Mental Health Composite Score is calculated by weighting the mental responses to the SF-12v2 more heavily. Both Physical Health Composite Scores and Mental Health Composite Scores range from 0 to 100. Although Physical Health Composite Scores and Mental Health Composite Scores may not have very intuitive meaning, higher scores reflect higher levels of health (i.e., better health). The Kessler Index is a summary measure of 6 questions intended to measure the level of non-specific psychological distress. Greater K6 scores reflect lower levels of mental health (i.e., worse mental health). We use the natural logarithms of Physical Health Composite Scores, Mental Health Composite Scores, and Kessler Index to mitigate skewed distribution.

\subsection{Access to Care and Health Behavior}

Access-to-care outcomes are binary variables indicating whether a person experienced a barrier to obtaining necessary health care services including being unable to get necessary medical care, being delayed in getting necessary medical care, being unable to get necessary dental care, being delayed in getting necessary dental care, being unable to get necessary prescribed medication, and being delayed in getting necessary prescribed medication.

Health behavior outcomes include binary indicators for whether a person currently smoke, whether a person currently engages in moderate or vigorous physical activity for a half hour or more at least three times a week, and whether a person's body mass index (BMI) falls within the normal weight range (i.e., $18.5 \leq \mathrm{BMI}<25$ ) as a crude proxy for general health behavior.

\subsection{Self-Employment}

The binary indicator of self-employment status (SelfEmp) is our main explanatory variable. It takes the value of 1 if a respondent was self-employed and 0 if a respondent was employed as a wage-earning individual. 
Table 1. Descriptive statistics by self-employment status $(N=13,435)$.

\begin{tabular}{|c|c|c|c|c|c|}
\hline & \multicolumn{2}{|c|}{ Self-employed workers $(\mathrm{N}=1481)$} & \multicolumn{2}{|c|}{ Salaried workers $(\mathrm{N}=11,954)$} & \multirow{2}{*}{ Two-sample t-test } \\
\hline & Mean & (s.d.) & Mean & (s.d.) & \\
\hline & \multicolumn{2}{|c|}{ (1) } & \multicolumn{2}{|c|}{ (2) } & $(1)-(2)$ \\
\hline \multicolumn{6}{|l|}{ Health outcomes } \\
\hline \multicolumn{6}{|l|}{ Physical health status } \\
\hline Perceived physical health & 3.83 & $(0.97)$ & 3.77 & $(0.96)$ & $0.058^{*}$ \\
\hline \multicolumn{6}{|l|}{ Validated physical health measures } \\
\hline Log of Physical Health Composite Score & 3.94 & $(0.20)$ & 3.94 & $(0.19)$ & -0.004 \\
\hline \multicolumn{6}{|l|}{ Medical conditions } \\
\hline Heart disease & 0.05 & & 0.04 & & 0.004 \\
\hline Stroke & 0.01 & & 0.01 & & -0.003 \\
\hline Diabetes & 0.06 & & 0.06 & & 0.010 \\
\hline Asthma & 0.07 & & 0.08 & & -0.010 \\
\hline High blood pressure & 0.23 & & 0.20 & & $0.028^{*}$ \\
\hline High cholesterol & 0.24 & & 0.20 & & $0.048^{* * *}$ \\
\hline Emphysema & 0.01 & & 0.01 & & 0.002 \\
\hline Joint pain & 0.32 & & 0.27 & & $0.057^{* * *}$ \\
\hline Arthritis & 0.13 & & 0.13 & & 0.0002 \\
\hline \multicolumn{6}{|l|}{ Mental health status } \\
\hline Perceived mental health & 4.11 & $(0.90)$ & 4.04 & $(0.20)$ & $0.068^{* *}$ \\
\hline \multicolumn{6}{|l|}{ Validate physical health measures } \\
\hline Log of Mental Health Composite Score & 3.93 & $(0.21)$ & 3.92 & $(0.22)$ & 0.010 \\
\hline Log of Kessler Index & 0.97 & $(0.80)$ & 0.99 & $(0.83)$ & -0.023 \\
\hline \multicolumn{6}{|l|}{ Access to care } \\
\hline Unable to get necessary medical care & 0.04 & & 0.03 & & $0.014^{* *}$ \\
\hline Delayed in getting necessary medical care & 0.06 & & 0.03 & & $0.011^{*}$ \\
\hline Unable to get necessary dental care & 0.06 & & 0.05 & & $0.012^{*}$ \\
\hline Delayed in getting necessary dental care & 0.05 & & 0.04 & & 0.010 \\
\hline Unable to get necessary prescribed medication & 0.02 & & 0.02 & & 0.002 \\
\hline Delayed in getting necessary prescribed medication & 0.02 & & 0.02 & & 0.002 \\
\hline \multicolumn{6}{|l|}{ Health behavior } \\
\hline Currently smoke & 0.19 & $(0.01)$ & 0.22 & $(0.41)$ & -0.023 \\
\hline Moderate/vigorous physical activity at least 3 times a week & 0.64 & $(0.48)$ & 0.58 & $(0.49)$ & $0.060^{* * *}$ \\
\hline Normal-weight BMI & 0.33 & $(0.47)$ & 0.33 & $(0.47)$ & -0.003 \\
\hline \multicolumn{6}{|l|}{ Covariates } \\
\hline Age & 45.1 & $(10.8)$ & 39.6 & $(12.2)$ & $5.551^{* * *}$ \\
\hline Female & 0.33 & & 0.50 & & $-0.125^{* * *}$ \\
\hline
\end{tabular}




\section{Continued}

\begin{tabular}{|c|c|c|c|}
\hline White (reference) & 0.83 & 0.76 & $0.075^{* * *}$ \\
\hline African American & 0.10 & 0.16 & $-0.062^{* * *}$ \\
\hline Native American & 0.01 & 0.01 & -0.008 \\
\hline Asian/Pacific Islander & 0.05 & 0.06 & -0.003 \\
\hline Multi-race & 0.01 & 0.02 & -0.003 \\
\hline \multirow[t]{2}{*}{ Hispanic } & 0.19 & 0.24 & $-0.043^{* * *}$ \\
\hline & \multicolumn{2}{|c|}{ Marital status } & \\
\hline Married (reference) & 0.68 & 0.57 & $0.108^{* * *}$ \\
\hline Widowed & 0.02 & 0.02 & 0.001 \\
\hline Divorced & 0.14 & 0.11 & $0.026^{* *}$ \\
\hline Separated & 0.03 & 0.03 & $-0.001^{* *}$ \\
\hline \multirow[t]{2}{*}{ Single } & 0.15 & 0.28 & $-0.133^{* * *}$ \\
\hline & \multicolumn{2}{|c|}{ Schooling } & \\
\hline$\leq$ High school (reference) & 0.17 & 0.21 & $-0.034^{* *}$ \\
\hline High school diploma & 0.44 & 0.45 & -0.008 \\
\hline College degree & 0.20 & 0.17 & $0.029^{* *}$ \\
\hline Master's/doctoral degree & 0.11 & 0.08 & $0.030^{* * *}$ \\
\hline \multirow[t]{2}{*}{ Full-time student } & 0.01 & 0.03 & $-0.026^{* * *}$ \\
\hline & \multicolumn{2}{|c|}{ Family income } & \\
\hline Poor income & 0.13 & 0.14 & -0.011 \\
\hline Low income & 0.14 & 0.15 & -0.008 \\
\hline Middle income & 0.32 & 0.33 & -0.018 \\
\hline \multirow[t]{2}{*}{ High income (reference) } & 0.42 & 0.38 & $0.037^{* *}$ \\
\hline & \multicolumn{2}{|c|}{ Occupation type } & \\
\hline Blue-collar (reference) & 0.37 & 0.53 & $-0.139^{* * *}$ \\
\hline White-collar & 0.04 & 0.04 & 0.004 \\
\hline Service & 0.03 & 0.04 & $-0.011^{*}$ \\
\hline \multirow[t]{2}{*}{ Metropolitan residence } & 0.83 & 0.85 & $-0.023^{*}$ \\
\hline & \multicolumn{2}{|c|}{ Census region } & \\
\hline West (reference) & 0.29 & 0.27 & 0.022 \\
\hline Northeast & 0.14 & 0.15 & -0.003 \\
\hline Midwest & 0.21 & 0.21 & -0.001 \\
\hline South & 0.35 & 0.37 & -0.018 \\
\hline
\end{tabular}

s.d. = standard deviation. Family income levels are classified into four categories based on 2007 federal poverty level (FPL): poor income (less than 125\% FPL), low income ( $125 \%$ to less than $200 \%$ FPL), middle income (200\% to less than $400 \%$ FPL), and high income (greater than or equal to $400 \%$ FPL). White-collar occupations include management, business, financial operation, and professional and related occupations. ${ }^{*} p<0.05 ;{ }^{* *} p<0.01 ;{ }^{* * *} p<0.001$.

There were 1481 self-employed persons (11 percent of the unweighted sample) in 2007. 


\subsection{Control Variables}

We control for demographic and socio-economic variables that may be correlated with our main independent and outcome variables. Covariates include age, female, race/ethnicity (African-American, Native American, Asian/ Pacific Islander, Multi-race, and Hispanic; white as a reference), marital status (widowed, divorced, separated, and single; married as a reference), level of schooling (high school graduate, college diploma, and master's or doctoral degree; less than high school as a reference), full-time student status, family income levels (poor, low, and middle income; high income as a reference), occupation type (white-collar and service job; blue-collar as a reference), metropolitan statistical area of residence, and geographic census regions (Northeast, Midwest, and South; West as a reference).

\section{METHODS}

\subsection{Empirical Model}

We estimate an empirical model of the following form:

$$
Y_{i}=f\left(S E_{i}, X_{i}, \varepsilon_{i}\right)
$$

where $i$ indexes an individual and $\varepsilon$ refers to the error term. $Y$ includes the various health measures as well as the measures of access to care and health behavior. $S E$ is the binary self-employment variable of main interest. $X$ is a vector of covariates, discussed above.

Since our dependent variables include both continuous and discrete measures, we take into account different function forms of the dependent variables when estimating Equation (1). For the continuous dependent variables such as In (Physical Health Composite Scores), In (Mental Health Composite Scores), and In (Kessler Index), we obtain ordinary least squares (OLS) estimates. For the ordinal response variables such as perceived physical and mental health status, we estimate ordered logit models. Probit models are estimated for the binary medical condition variables as well as for the access-to-care and health behavior outcomes. All estimates are surveyweighted and adjusted for the complex design of the MEPS survey.

In a linear model such as an OLS model, the coefficient on the self-employment variable captures the marginal effect of self-employment on the outcomes. For non-linear models such as ordered logit and probit, we calculate the marginal effect of self-employment as a mean difference in predicted probabilities of the outcome between self-employed and wage-earning individuals $[21,22]$. We defer detailed discussion to the result section.

\subsection{Endogenous Selection into Self-Employment}

One complication in our empirical models is that selfemployment may be endogenous. This situation would arise if healthier individuals choose to be self-employed, rather than to become wage-earning individuals, or if there are unobserved individual profiles associated with both self-employment and health measures. This situation causes the self-employment variable to be correlated with the error term $\left(\varepsilon_{i}\right)$, leading to biased and inconsistent estimates.

To test and address the potential sources of bias, we carry out instrumental variables analyses. We obtain efficient two-step generalized method of moments (GMM) estimators for the continuous health variables. We obtain consistent two-stage residual inclusion (2SRI) estimators for the ordinal and binary health measures because the standard instrumental variables method may lead to inconsistent estimates in nonlinear models [23-25].

Instruments must meet two fundamental requirements. First, there must be a non-zero correlation between selfemployment and instruments. Second, instruments should not be correlated with the error terms in the above Equation (1). We reviewed the literature to find theoretically plausible instruments that meet the first condition. Our prospective instruments include the number of self-employed family members, a dichotomous immigrant status variable, years of labor market experience, the number of children, and having uninsured children. Having selfemployed family members increases the probability of entering self-employment possibly due to intra-household transfers of human capital [26,27]. Borjas [28] and Yuengert [29] report that the rate of self-employment is higher among immigrants than among US-born workers. Many older workers appear to transition from salaried work into self-employment before they complete retirement [26]. There appears a positive correlation between self-employment status and the number of children [30]. The high uninsurance rate of the self-employed may lead to a greater uninsurance for their children. Therefore, a dichotomous indicator for having uninsured children is included as a potential instrument.

We rigorously test whether the prospective instruments meet the above two criteria to become valid. We test the explanatory power of the instruments in the first stage equation using individual $t$-test and joint $F$-test. Staiger and Stock [31] recommend 10 or greater F statistic as evidence of strong instruments. The validity of the prospective instruments is further evaluated for the exclusion restrictions through the Hansen $J$ statistic [32]. The $J$ test evaluates the joint null hypothesis that instruments are uncorrelated with the error and thus are validly excluded from Equation (1). The $J$ statistic from two-step 
GMM is used for the nonlinear models.

Table 2 presents a sample result of a first-stage regression. Having uninsured child and the number of selfemployed family members are used as valid instruments based on results of the diagnostic tests for the strength and validity of instruments. As shown, the instruments are highly, individually significant. Table $\mathbf{3}$ shows that in all models our instruments are jointly significant and validly excluded from the main equations.

\section{RESULTS}

\subsection{Descriptive Results on the Relationship between Self-Employment and Health}

Table 1 reports unweighted descriptive statistics for the outcomes and the covariates by self-employment status. Self-employment is significantly associated with a greater level of perceived physical health status. The two-sample $t$-test shows that the difference is statistically significant. The self-employed have a lower average Physical Health Composite Score than wage-earning individuals, but this difference was statistically insignificant. Although differences in various medical conditions are somewhat mixed, the descriptive statistics suggest that the self-employed have a greater probability of having high blood pressure, high cholesterol, and joint pain. In terms of mental health, self-employed individuals appear to have better perceived mental health. However, there is no statistically significant difference in clinically validated scores such as the Mental Health Composite Score and the Kessler Index of non-specific psychological distress.

Self-employed and wage-earning individuals also appear to be statistically different in other ways. The selfemployed on average is older than wage-earning individuals. The self-employed are more likely to be male, white, non-Hispanic, married workers, or have higher education levels. They are more likely to report high family income, and live outside a metropolitan statistical area.

\subsection{Effect of Self-Employment on Health}

Table 4 reports results of the multivariate models. In order to preserve space, only marginal effects of selfemployment are presented. Full model results can be requested from the authors. The coefficients are interpreted as marginal probabilities for the continuous health measures such as Physical Health Composite Score, Mental Health Composite Score, and the Kessler Index.

In the regression models for discrete outcomes, the coefficients cannot be interpreted directly, and thus have been transformed to marginal probabilities [21,22]. For the ordered logit model, where the level of health is a latent variable, we standardize the marginal change in
Table 2. First-stage regression on self-employment.

\begin{tabular}{|c|c|}
\hline & Coefficient (s.e.) \\
\hline \multicolumn{2}{|c|}{ Instrumental variables } \\
\hline Having uninsured child & $0.021^{* *}(0.007)$ \\
\hline Number of self-employed family members & $0.201^{* * *}(0.016)$ \\
\hline \multicolumn{2}{|l|}{ Covariates } \\
\hline Age & $0.004^{* * *}(0.001)$ \\
\hline Female & $-0.066^{* * *}(0.007)$ \\
\hline \multicolumn{2}{|c|}{ Race/ethnicity (reference: white) } \\
\hline African American & $-0.043^{* * *}(0.009)$ \\
\hline Native American & $0.010(0.041)$ \\
\hline Asian/Pacific Islander & $-0.049^{* * *}(0.012)$ \\
\hline Multi-race & $-0.013(0.027)$ \\
\hline Hispanic & $-0.032^{* * *}(0.009)$ \\
\hline \multicolumn{2}{|c|}{ Marital status (reference: married) } \\
\hline Widowed & $0.009(0.036)$ \\
\hline Divorced & $0.014(0.012)$ \\
\hline Separated & $0.020(0.024)$ \\
\hline Single & $-0.007(0.009)$ \\
\hline \multicolumn{2}{|c|}{ Schooling (reference: less than high school) } \\
\hline High school diploma & $0.022^{* *}(0.008)$ \\
\hline College degree & $0.037^{* * *}(0.011)$ \\
\hline Master's/doctoral degree & $0.048^{* * *}(0.014)$ \\
\hline Full-time student & $-0.026^{*}(0.013)$ \\
\hline \multicolumn{2}{|c|}{ Family income (reference: high income) } \\
\hline Poor & $0.081^{* * *}(0.014)$ \\
\hline Low & $0.044^{* * *}(0.012)$ \\
\hline Middle & $0.020^{*}(0.008)$ \\
\hline \multicolumn{2}{|l|}{ Occupation type } \\
\hline White-collar & $0.013(0.016)$ \\
\hline service & $-0.016(0.016)$ \\
\hline Metropolitan residence & $-0.018(0.011)$ \\
\hline \multicolumn{2}{|c|}{ Census region (reference: West) } \\
\hline Northeast & $-0.030^{* *}(0.011)$ \\
\hline Midwest & $-0.034^{* * *}(0.010)$ \\
\hline South & $-0.020^{*}(0.010)$ \\
\hline Intercept & $-0.018(0.023)$ \\
\hline$N$ & 12,061 \\
\hline$R^{2}$ & 0.1891 \\
\hline
\end{tabular}

s.e. $=$ standard error. ${ }^{*} p<0.05 ;{ }^{* *} p<0.01 ;{ }^{* * *} p<0.001$. 
Table 3. Diagnostic tests for the validity of instruments.

\begin{tabular}{|c|c|c|}
\hline Outcome & Strength of the instruments: $F$ test $^{\mathrm{a}}$ & Exclusion restrictions: $J$ test ( $p$-value $)^{b}$ \\
\hline \multicolumn{3}{|l|}{ Physical health } \\
\hline Perceived physical health & $\mathrm{F}(2,12,034)=81.9$ & $x_{1}^{2}=0.043(p=0.836)$ \\
\hline $\ln (\mathrm{PCS})$ & $\mathrm{F}(2,11,059)=78.3$ & $x_{1}^{2}=0.531(p=0.466)$ \\
\hline Stroke & $F(2,12,006)=81.8$ & $x_{1}^{2}=0.563(p=0.453)$ \\
\hline Diabetes & $\mathrm{F}(2,11,999)=81.9$ & $x_{1}^{2}=1.228(p=0.268)$ \\
\hline Asthma & $\mathrm{F}(2,11,997)=81.4$ & $x_{1}^{2}=0.090(p=0.764)$ \\
\hline High blood pressure & $\mathrm{F}(2,11,979)=81.2$ & $x_{1}^{2}=2.959(p=0.085)$ \\
\hline High cholesterol & $\mathrm{F}(2,11,917)=7.58$ & $x_{1}^{2}=0.518(p=0.472)$ \\
\hline Emphysema & $F(2,12,008)=81.9$ & $x_{1}^{2}=0.111(p=0.739)$ \\
\hline Joint pain & $F(2,11,965)=81.99$ & $x_{1}^{2}=3.006(p=0.083)$ \\
\hline Arthritis & $\mathrm{F}(2,11,973)=13.0$ & $x_{1}^{2}=1.447(p=0.229)$ \\
\hline \multicolumn{3}{|l|}{ Mental health } \\
\hline Perceived mental health & $\mathrm{F}(2,12,029)=82.0$ & $x_{1}^{2}=0.226(p=0.051)$ \\
\hline $\ln (\mathrm{MCS})$ & $F(2,11,065)=78.2$ & $x_{1}^{2}=0.738(p=0.635)$ \\
\hline $\ln (\mathrm{K} 6)$ & $F(2,10,881)=77.8$ & $x_{1}^{2}=0.377(p=0.539)$ \\
\hline \multicolumn{3}{|l|}{ Access to care } \\
\hline Unable to get necessary medical care & $\mathrm{F}(3,12,021)=59.7$ & $x_{1}^{2}=4.245(p=0.120)$ \\
\hline Delayed in getting necessary medical care & $F(3,12,015)=59.5$ & $x_{1}^{2}=0.738(p=0.692)$ \\
\hline Unable to get necessary dental care & $\mathrm{F}(3,12,015)=59.3$ & $x_{1}^{2}=3.744(p=0.154)$ \\
\hline Delayed in getting necessary dental care & $F(3,12,009)=59.4$ & $x_{1}^{2}=1.909(p=0.385)$ \\
\hline Unable to get necessary prescribed medication & $\mathrm{F}(3,12,011)=60.1$ & $x_{1}^{2}=0.437(p=0.804)$ \\
\hline Delayed in getting necessary prescribed medication & $F(3,12,013)=60.1$ & $x_{1}^{2}=0.400(p=0.819)$ \\
\hline \multicolumn{3}{|l|}{ Health behavior } \\
\hline Currently smoke & $F(2,10,953)=77.2$ & $x_{1}^{2}=0.065(p=0.800)$ \\
\hline Moderate/vigorous physical activity at least 3 times a week & $F(1,11,930)=13.7$ & $\mathrm{~N} / \mathrm{A}$ \\
\hline Seat belt & $\mathrm{F}(3,11,967)=58.1$ & $x_{1}^{2}=1.910(p=0.385)$ \\
\hline BMI & $F(2,11,685)=79.5$ & $x_{1}^{2}=0.023(p=0.880)$ \\
\hline
\end{tabular}

${ }^{\mathrm{a}}$ Instruments with a $F$ statistic greater than 10 in general are considered as being strong; ${ }^{\mathrm{b}} \mathrm{J}$ statistic must be insignificant for instruments to be valid.

the latent health variable by the estimated standard deviation of the latent variable [33]. Therefore, the marginal effects from the ordered logit models for perceivedphysical and mental health are interpreted as changes in standard deviations of the latent health level for self-employed individuals in comparison to wageearning individuals. For example, the marginal effect on perceived physical health indicates that the health of the self-employed is 0.069 standard deviations higher than that of wage-earning individuals (see Column 1).

Marginal effects in the probit model for binary out- comes are computed as differences in average predicted probabilities between the self-employed and wage-earning individuals, e.g., the self-employed have the approximately 11.6 percentage-point lower risk of diabetes relative to wage-earning individuals (see Column 1). Standard errors are based on 1000 bootstrap repetitions.

Results from the "usual" estimation methods without correction for selection bias, i.e., multivariate linear regression, probit, and ordered logit models-are reported in Column 1. Self-employment is strongly and positively associated with both perception measures and clinical 
Table 4. Marginal effects of self-employment on health outcomes.

\begin{tabular}{|c|c|c|}
\hline Outcome & Usual methods: OLS/logit/ordered logit models (1) & $\begin{array}{l}\text { Instrumental variables methods: } \\
\text { Two-step GMM/2SRI models (2) }\end{array}$ \\
\hline \multicolumn{3}{|l|}{ Physical health } \\
\hline Perceived physical health & $0.069^{* * *}(0.021)$ & $0.19(0.10)$ \\
\hline In (Physical Health Composite Score) & $0.009(0.006)$ & $0.017(0.033)$ \\
\hline Stroke & $-0.005^{*}(0.002)$ & $-0.005(0.031)$ \\
\hline Diabetes & $-0.116^{*}(0.054)$ & $-0.119^{* *}(0.037)$ \\
\hline Asthma & $-0.005(0.009)$ & $-0.002(0.055)$ \\
\hline High blood pressure & $-0.023^{*}(0.012)$ & $-0.119^{* *}(0.037)$ \\
\hline High cholesterol & $-0.028^{*}(0.011)$ & $-0.259^{* * *}(0.048)$ \\
\hline Emphysema & $-0.0004(0.0024)$ & $-0.008(0.031)$ \\
\hline Joint pain & $0.012(0.013)$ & $-0.288^{* * *}(0.051)$ \\
\hline Arthritis & $-0.026^{* *}(0.009)$ & $-0.177^{* * *}(0.038)$ \\
\hline \multicolumn{3}{|l|}{ Mental health } \\
\hline Perceived mental health & $0.063^{* * *}(0.019)$ & $0.176(0.097)$ \\
\hline ln (Mental Health Composite Score) & $0.004(0.007)$ & $0.026(0.036)$ \\
\hline $\ln ($ Kessler Index) & $-0.003(0.026)$ & $-0.09(0.14)$ \\
\hline
\end{tabular}

All estimates are survey-weighted. Standard errors are in parentheses and are adjusted for complex survey design. Bootstrapped standard errors (based on 1000 repetitions) are reported for discrete health-outcome models. ${ }^{*} p<0.05 ;{ }^{* *} p<0.01 ;{ }^{* * *} p<0.001$.

indexes of physical health. The effect of self-employment on perceived physical health status is positive and significant, meaning that the self-employed are more likely than wage-earning individuals to feel they are physically healthy. The marginal effect on self-employment is also positive for In (Physical Health Composite Score), but is not statistically significant at the 95 percent level. Marginal effects on the medical conditions are and negative and statistically significant for stroke, diabetes, high blood pressure, high cholesterol, and arthritis. The marginal effects appear to be large in magnitude. For example, self-employment is associated with the 2.3 and 2.8 percentage-point lower risk of having high blood pressure and high cholesterol, respectively.

The usual estimation methods in Column 1 find a positive and significant relationship between self-employment and perceived mental health status. However, the marginal effect of self-employment in the clinically validated mental health measures, i.e., In (Mental Health Composite Score) and In (Kessler Index)-do not support this association.

Instrumental variables results that address the issue of self-selection into self-employment are reported in Column 2, and are in alignment with those from the usual estimation methods in Column 1, with some exceptions. As discussed above, in the usual models, selfemployment significantly increases perceived physical health and reduces the likelihood of stroke. In the instrumental variables models, the direction of the effect stays the same, but significance is lost. For the joint pain outcome, the instrumental variables result suggests that the self-employment significantly reduces the likelihood of joint pain by approximately 29 percentage points. Overall, the results of the usual model and the instrumental variables model suggest that self-employment is a significant variable in terms of reducing the likelihood of specific physical health conditions.

Regarding mental health, the instrumental variables results reported in Column 2 suggest that self-employment is not significantly associated with any measure of mental health.

\subsection{Effect of Self-Employment on Access to Health Care and Health Behavior}

Table 5 presents effects of self-employment on the likelihood of experiencing a barrier to health care and the likelihood of engaging in health-related behavior. As shown in Column 1, marginal effects from the usual models show that self-employment is positively significantly associated with the likelihood of being unable to obtain necessary medical care, delay in obtaining necessary medical care, and being unable to obtaining necessary dental care. However, instrumental variables 
Table 5. Marginal effects of self-employment on access to care and health behavior.

\begin{tabular}{ccc}
\hline Outcome & Usual logit model (1) & 2SRI-logit model (2) \\
\hline Access to care & & $-0.008(0.006)$ \\
Unable to get necessary medical care & $0.018^{*}(0.007)$ & $-0.032(0.023)$ \\
Delayed in getting necessary medical care & $0.014^{*}(0.007)$ & $-0.048(0.023)$ \\
Unable to get necessary dental care & $0.021^{* *}(0.008)$ & $-0.011(0.031)$ \\
Delayed in getting necessary dental care & $0.007(0.006)$ & $-0.029(0.026)$ \\
Unable to get necessary prescribed medication & $0.003(0.004)$ & $-0.013(0.021)$ \\
Delayed in getting necessary prescribed medication & $0.003(0.005)$ & $-0.113^{*}(0.049)$ \\
Health behavior & $-0.015(0.014)$ & $0.437^{* * *}(0.050)$ \\
Currently smoke & $0.054^{* * *}(0.015)$ & $0.201^{* * *}(0.045)$ \\
\hline Normal-weight BMI & $0.025(0.016)$ & \\
\hline
\end{tabular}

All estimates are survey-weighted. Bootstrapped standard errors reported in parentheses are based on 1000 repetitions, and are adjusted for complex survey design. ${ }^{*} p<0.05 ;{ }^{* *} p<0.01 ;{ }^{* * *} p<0.001$.

results in Column 2 do not show significant difference in the access-to-care measures between self-employed and wage-earning individuals.

In term of health behavior, the result from the usual model shows that self-employment is positively associated with the likelihood of engaging in moderate or vigorous physical activity for a half hour or more at least 3 times a week. Instrumental variables results show that self-employed individuals are less likely than wageearning individuals to currently smoke, are more likely to participate in moderate or vigorous physical activity, and have a greater chance to have BMI of the normal-weight range.

\section{DISCUSSION}

This study finds that self-employed individuals in the US are physically healthy, or healthier than wage-earners, with health conceptualized as risk of illness. The identified difference appears to be significant in magnitude. We do not find a statistically significant difference in the subjective physical health measure (i.e., perceived physical health) and the other less-subjective, validated indexes. In total, despite the relative lack of health insurance among self-employed persons as compared to wageearning persons, self-employment does not appear to lead to poorer physical health status.

We find no significant relationship between self-employment and mental health. This result might be attributed, in part, to stigma or cultural norms, which prevent some individuals from admitting mental health problems [34]. Given the underlying issues related to the mental health data, we strongly advocate for more research on the relationship between self-employment and mental health.

We find that self-employed individuals do not experience a greater barrier to access to necessary health care. This finding is in line with research by Perry and Rosen [19] that finds the same rates of utilization of various medical care services between the self-employed and wage-earning populations. A potential reason for our finding is that despite a higher rate of being uninsured among self-employed individuals in the US, the selfemployed may be able to finance their own health care using their incomes or accumulated savings [17].

We also find that self-employed individuals are more likely than wage-earning individuals to engage in healthpromoting activities, perhaps due to greater flexibility in making room for health promotion activities into their schedule. We believe that this finding supports the importance of health behavior in the production of health.

Minorities and women have made tremendous strides, increasing their proportion of the total self-employed, with the largest gains coming from the Latino population. The number of self-employed Hispanics more than doubled from 2000 to 2008 , as their share of the self-employed population rose from 5.6 to 10.2 percent [18]. Despite the time trend in demographics of the self-employed population and continued health disparities among different racial/ethnicity groups, we do not find worse health for the self-employed. A potential reason is that self-employment status may overcome health disparities across race/ethnicity groups.

In a supporting analysis, we estimate instrumental variables models of health status by Hispanic ethnicity and obtain the same interpretations as those from Table 4, 
i.e., self-employed individuals are as physically and mentally healthy as wage-earning individuals (results are available from the authors). Given the changing demographics in the United States, an in-depth analysis that focuses on the influence of self-employment for the hispanic population is warranted.

Our findings have an important policy implication, especially for countries that endeavor to achieve universal health insurance coverage. The recently enacted health care reform law in the US, i.e., Affordable Care Act of 2010, is profoundly changing the US health care system [11]. Notwithstanding the exemptions and financial assistance that small businesses will receive from the federal government to offer health insurance to their employees, there has been substantial push-back from small businesses and their employees regarding the components (i.e., penalties and individual mandate) of the Affordable Care Act. The results of this study allow for a deeper understanding of the self-employed and the reluctant movement towards a universal health insurance system.

Economic theory provides a consistent view in that the opportunity costs of foregoing health insurance would be lower for those in better health status; alternatively, net benefit (marginal benefit minus marginal cost) from purchasing health insurance would be smaller for those in better health [35]. According to a 2007 national survey, approximately 25 percent of US adults aged 18 to 64 responded that health insurance was not worth the money it costs, and 11 percent of adults stated that they did not need coverage because they were healthy enough [36]. Further, researchers have found that perceived health substantially explains the differences in health insurance coverage across demographic and socioeconomic groups [36]. Therefore, self-employed individuals with good health status may conclude that it is better to remain uninsured and self-insure.

We cannot conclude in this study the extent to which health status of the self-employed accounts for the failure to have or secure health insurance, as there may be other influential factors, such as costs. However, beginning in 2014, self-employed individuals in the US will have greater access to health insurance than ever before. This study can serve as a benchmark with which to assess the effects of the Affordable Care Act on the relationship between self-employment and health.

\section{REFERENCES}

[1] World Health Organization (2003) Social determinants of health: The solid facts. 2nd Edition, World Health Organization, Geneva.

http://www.euro.who.int/_ data/assets/pdf_file/0005/984 38/e81384.pdf

[2] Benz, M. and Frey, B.S. (2004) Being independent raises happiness at work. Swedish Economic Policy Review, 12, 97-138.

[3] Blanchflower, D.G. (2000) Self-employment in OECD countries. Labour Economics, 7, 471-505. http://dx.doi.org/10.1016/S0927-5371(00)00011-7

[4] Blanchflower, D.G. and Oswald, A. (1998) What makes an entrepreneur? Journal of Labor Economics, 16, 26-60. http://dx.doi.org/10.1086/209881

[5] Anderson, P. (2008) Happiness and health: Well-being among the self-employed. Journal of Socio-Economics, 37, 213-216.

http://dx.doi.org/10.1016/j.socec.2007.03.003

[6] Taylor, M. (2004) Self-employment in Britain: When, who and why? Swedish Economic Policy Review, 12, 139-173.

[7] van der Hulst, M. (2003) Long work hours and health. Scandinavian Journal of Work, Environment, \& Health, 29, 171-188.

[8] Monheit, A.C. and Vistnes, J.P. (2006) Research findings \#2: Health insurance status of workers and their families, 1996. Agency for Healthcare Research and Quality, Rockville.

[9] Carper, K. and Beauregard, K. (2009) Characteristics of uninsured workers: Estimates for the US civilian noninstitutionalized population 19 - 64 years of age, 2006: Statistical brief No. 257. Agency for Healthcare Research and Quality, Rockville.

[10] Carroll, W. (2005) The health insurance status of US workers, 2003: Estimates for civilian non-institutionalized workers ages 16 - 64: Statistical brief \#71. Agency for Healthcare Research and Quality, Rockville.

[11] Reinhardt, U.E. (2013) Much ado about nothing: The US Supreme Court's rules on health reform. Health Economics, Policy and Law, 8, 125-132.

[12] Lewin-Epstein, N. and Yuchtman-Yaar, E. (1991) Health risks of self-employment. Work and Occupations, 18, 291-312. http://dx.doi.org/10.1177/0730888491018003003

[13] Stephan, U. and Roesler, U. (2010) Health of entrepreneurs versus employees in a national representative sample. Journal of Occupational and Organizational Psychology, 83, 717-738. http://dx.doi.org/10.1348/096317909X472067

[14] Hundley, G. (2001) Why and when are the self-employed more satisfied with their work? Industrial Relations, 40, 293-316. http://dx.doi.org/10.1111/0019-8676.00209

[15] Jamal, M. (1997) Job stress, satisfaction, and mental health: an empirical examination of self-employed and non-self-employed Canadians. Journal of Small Business Economics, 35, 48-57.

[16] Dolinsky, A.L. and Caputo, R.K. (2003) Health and female self-employment. Journal of Small Business Management, 41, 233-241.

http://dx.doi.org/10.1111/1540-627X.00079

[17] Perry, C.W. and Rosen, H.S. (2001) The self-employed are less likely to have health insurance than wage-earners. So what? NBER Working Paper, No. 8965, National Bureau of Economic Research, Washington DC. 
[18] US Small Business Administration (2010) The small business economy: A report to the President. http://www.sba.gov/sites/default/files/sb econ2010.pdf

[19] Perry, C.W. and Rosen, H.S. (2001) Insurance and the utilization of medical services among the self-employed. NBER Working Paper, No. 8490, National Bureau of Economic Research, Washington DC.

[20] Ware, J.E., Kosinski, M., Turner-Bowker, D.M. and Gandek, B. (2002) How to score version 2 of the SF-12 health survey. Quality Metrics, Lincoln.

[21] Ai, C. and Norton, E.C. (2003) Interaction terms in logit and probit models. Economic Letters, 80, 123-129. http://dx.doi.org/10.1016/S0165-1765(03)00032-6

[22] Norton, E.C., Wang, H. and Ai, C. (2004) Computing interaction effects and standard errors in logit and probit models. Stata Journal, 4, 154-167.

[23] Rivers, D. and Vuong, Q.H. (1988) Limited information estimators and exogeneity tests for simultaneous probit models. Journal of Econometrics, 39, 347-366. http://dx.doi.org/10.1016/0304-4076(88)90063-2

[24] Blundell, R.W. and Smith, R.J. (1989) Estimation in a class of simultaneous equation limited dependent variable models. Review of Economic Studies, 56, 37-58. http://dx.doi.org/10.2307/2297748

[25] Terza, J.V., Basu, A. and Rathouz, P.J. (2008) Two-stage residual inclusion estimation: Addressing endogeneity in health econometric modeling. Journal of Health Economics, 27, 531-543. http://dx.doi.org/10.1016/j.jhealeco.2007.09.009

[26] Bruce, D. (1999) Do husbands matter? Married women entering self-employment. Small Business Economics, 13, 317-329. http://dx.doi.org/10.1023/A:1008179214572

[27] Lin, Z., Picot, G. and Compton, J. (2000) The entry and exit dynamics of self-employment in Canada. Small Business Economics, 15, 105-125. http://dx.doi.org/10.1023/A:1008150516764

[28] Borjas, G.J. (1986) The self-employment experience of immigrants. Journal of Human Resources, 21, 485-506. http://dx.doi.org/10.2307/145764

[29] Yuengert, A.M. (1993) Testing hypotheses of immigrant self-employment. Journal of Human Resources, 30, 194204. http://dx.doi.org/10.2307/146196

[30] Broussard, N., Chami, R. and Hess, G.D. (2003) Why do self-employed parents have more children? CESifo Working Paper, No. 1103, Center for Economic Studies \& Ifo Institute, Munich.

[31] Staiger, D. and Stock, J.H. (1997) Instrumental variables regression with weak instruments. Econometrica, 65, 557-586. http://dx.doi.org/10.2307/2171753

[32] Hansen, L. (1982) Large sample properties of generalized method of moments estimators. Econometrica, 50, 10291054. http://dx.doi.org/10.2307/1912775

[33] Long, J.S. and Freese, J. (2006) Regression models for categorical dependent variables using Stata. 2nd Edition, Stata Press, College Station.

[34] US Department of Health and Human Services (1999) Mental health: A report of the Surgeon General-Executive summary. US Department of Health and Human Services, Rockville.

[35] Pauly, M.V. (1968) The economics of moral hazard: Comment. American Economic Review, 58, 531-537.

[36] Cohen, S.B. (2009) Attitudes toward health insurance and their persistence over time, adults 2006-2007: Statistical brief No. 260.

http://meps.ahrq.gov/mepsweb/data_files/publications/st2 $\underline{60 / \text { stat260.shtml }}$ 